\title{
Just-In-Time: Case Studies Of Supplier Relationships Across Industries
}

\author{
Dean R. Manna, (E-mail: manna@rmu.edu), Robert Morris University
}

\begin{abstract}
Just-in-time (JIT) is a well-established philosophy that seeks to sustain a competitive advantage and result in greater overall returns through waste elimination and variability reduction. One component of the philosophy is the relationships with suppliers. These relationships are vital to the success of organizations regardless of the industry. The automotive, electronic, healthcare, and steel industries engage in JIT practices in differing fashions but all seek the same goal of sustaining a competitive advantage over the competition. The automotive and electronic industries rely heavily on information sharing. A critical component of the healthcare industry is seeking out long-term contracts with suppliers in order to assure quality and timeliness of deliveries. The steel industry has elements of the JIT philosophy but has been forced to vertically integrate many of its productions due to the rising costs of raw materials. Depending on the industry a firm competes in, and the relationship it has with its suppliers determines the manner in which it practices the JIT philosophy.
\end{abstract}

\section{INTRODUCTION}

\section{JIT And The Automobile Industry}

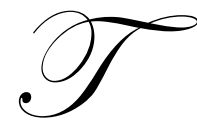

he JIT philosophy was implemented initially by Toyota in the 1950s. By the 1970 's, many Japanese car manufacturers had implemented this lean way of thinking. Since then, others have followed in the footsteps of Toyota, by using variations of JIT management techniques to reduce costs and increase efficiency (Smith and Flanegin, 2004). Arguably, the most important area of JIT is supplier partnerships (Smith, 2003; Smith and Offodile, 2007). Many decisions must be made when choosing suppliers to support a business using a JIT philosophy. In the automobile industry, for example, perhaps one of the most important aspects of supplier partnerships is to minimize the number of suppliers (preferably keeping them close to the manufacturing plants), to resist the temptation of vertical integration, and to work with the suppliers openly to include them in the engineering of most, if not all, aspects of the automobile and many manufacturing industries.

\section{CASE STUDIES OF JIT}

\section{JIT And The Automobile Industry}

Many manufacturers in the automobile industry have adopted the JIT management philosophy since the 1970s when they began working towards a lean production process. Besides the Japanese, who are known for first implementing the JIT philosophy, others have worked on perfecting certain aspects of JIT. In the automobile industry, supplier relations are essential to the success of the JIT philosophy. For example, the Italian car manufacturer, Fiat had begun revolutionizing relationships with suppliers by setting up partnerships with those suppliers providing various parts to the finished goods.

By partnering with their suppliers, Fiat has recognized the importance of increased quality and decreased costs (Camuffo and Volpato, 2000). Since Fiat chose to partner with its suppliers, their number of suppliers decreased and longer-term relationships were developed to emphasize assistance in the development process, trust building, and JIT coordination. Fiat decreased the degree of vertical integration due to increased external 
outsourcing, which exemplified quality and efficiency improvements. Fiat had particularly concentrated on hi-tech parts, and subsystems of components for outsourcing purposes. Fiat has developed a 700,000 square foot assembly plant in Melfi (South Italy) dedicated to suppliers for the production of critical components for suppliers that have experienced difficulty in transporting these items. This location, which is adjacent to the assembly plant, was developed to minimize outsourcing lead times.

Advantages to supplier partnerships exist because suppliers find it difficult to trust customers that develop aggressive market relationships, based on competitive bids and on a short-term basis. The supplier may feel that by partnering with a manufacturer, communication and coordination will be improved (Smith, 2003; Smith and Offodile, 2007).

On occasion, suppliers have disputed with Fiat about who is responsible for JIT malfunction-related costs. To address this, Fiat has shifted the responsibility to the suppliers (and they have accepted) to service the assembly line of their newest models, using a system of delivery for parts that must arrive in the same sequence as the assembly line (Camuffo and Volpato, 2000).

Vertical integration can avoid costs associated with market transactions and can help protect valued assets; however it can also lead to higher production costs. Long-term partnerships with suppliers promote increased investments in certain assets, and can be a substitute for vertical integration at times. As uncertainty or technological change increases, firms should reduce vertical integration and increase their alliances flexibility.

These two strategies can affect the manufacturers and supplier's bargaining power and the incentive to make long-term investments in partnerships. Buyers can negotiate the price of components, but suppliers would be less willing to work with this type of customer because the customer would absorb all the profits and the price would be reduced. When customers give up this bargaining power, long-term relationships with suppliers can substitute for vertical integration of activities involving specific transactions because the costs are outsourced and better partnering relationships are built.

In 1986, GM employed 3000 purchasing personnel, and produced 2000 cars per buyer. Toyota employed 340 buyers and produced 10,590 cars per buyer, even though GM was more vertically integrated (Doran, 2001). GM executives explained that most activities were geared to making sure that GM wasn't taken advantage of by an undermined supplier. Since 1988, Chrysler has reduced its number of buyers by $30 \%$. These changes were made possible by reducing the number of suppliers and pre-selecting suppliers based on quality and performance, eliminating competitive bidding.

In the last ten years, Chrysler has requested suppliers eliminate sales representatives and shift those resources to engineering, which has contributed to Chrysler's increased share of the U.S. car market (from 12.2\% in 1987 to $14.7 \%$ in 1994). Its return on assets (ROA) has been the highest among U.S. automakers since 1992, and its profit per vehicle has increased from $\$ 250$ in 1985-1989 to $\$ 2,110$ in 1994 (Foudy, 2007).

In the Japanese system, suppliers are used in the development process to assume significant responsibility, and communicate extensively with product and process engineers (Domingo, 1995). As a result, Japanese automakers develop new vehicles about 30\% faster than U.S. automakers. After adopting voice relationships, Chrysler reduced the amount of time it takes to develop a new vehicle from an average of 234 weeks in the 1980s to 183 weeks for the LH program, without increasing the size of its engineering staff.

Automobile manufacturers that used to deal with hundreds, even thousands, of suppliers are now limiting the number of suppliers they use. Many U.S.-based firms hope to fully outsource most of their cars and deal with only a very limited number of suppliers. For example, GM recently moved to select five suppliers to completely manage the interiors of its cars. Automobile manufacturers, such as BMW and Daimler Chrysler's Mercedes, have usually relied on high-tech suppliers to maintain their edge and that dependence is increasing. They need a supplier to have a global presence, and as a result of the demands of automobile manufacturers, consolidation of suppliers has grown substantially. For example, between 1994 and 1998, the value of merger and acquisitions among auto 
suppliers grew from $\$ 2.1$ to $\$ 18.9$ billion annually, and the average deal size grew from $\$ 73$ million in 1994 to $\$ 205$ million in 1998.

The key to the relationships of both Mercedes and BMW with their suppliers is their ability to introduce the latest innovations into their cars. They are supported by a very strong automobile supplier industry with leading names like Bosch, Siemens Automotive, Mahle, and Hella. DaimlerChrysler has implemented a new program to work with its suppliers called the Tandem program, which invites key suppliers to discuss the whole car concept with suppliers and communicate the necessary quality and other features of the car it expects from the suppliers. The program allows suppliers to work with automobile manufacturers to supply ideas.

Lacking the size to pressure suppliers or other means of influence, BMW approaches suppliers as long-term relationships and tries to be a better customer. BMW's purchasing strategy focuses on careful research and selection in finding sophisticated suppliers as partners. It communicates frequently with suppliers during development, depending on their technical competence at BMW. Once BMW has begun working with a supplier, they offer a commitment to the life of the model and will likely continue working with the supplier unless problems arise. BMW's strategy is to be "the best customer" a supplier has.

Even as a premium brand, cost is critical and remains highly sensitive. BMW has also tried to communicate its firm's strategies to suppliers so they can react to their needs more quickly. BMW has about 150 suppliers of which only 60 are core suppliers. BMW is outsourcing the actual production of its new X5 SUV to Steyr Daimler Puch, an Austrian subsidiary of Canadian suppler Magna, who will completely assemble the new vehicle under contract. As a result, BMW's role in producing cars is steadily diminishing over time.

Some Japanese car manufacturers have looked to own stakes in suppliers. Economists in the Japanese economy have viewed this decision as very important. The decision can solidify existing relations with partners and act as an indicator of commitment to a relationship. Ownership can also be seen as a seal of approval by a manufacturer and enhance the reputation of a supplier when dealing with others. This creation of goodwill in a supplier is an important intangible that can benefit both parties.

A JIT manufacturer trains its suppliers to reduce discrepancies in input quality and delivery. Establishing local and foreign partnerships with suppliers can often lead to better quality and more reliable delivery of raw materials and supplies. To help make suppliers easier to work with, the number of suppliers should be reduced to maximize the efficiency of JIT. Toyota has about 200 suppliers, while Ford has about 8,000. An advantage of assembling supplier partnerships is that suppliers will not resort to increasing prices when the raw materials fluctuate in costs.

In effective supplier partnerships, both parties must continually exchange information and ensure effective communication. Suppliers to Nissan are required to use continuous improvement techniques, take total responsibility for the delivery of zero defects, and develop quality systems and controls that accommodate these requirements. In addition, Nissan's perspective suppliers are expected to manage product design, material specification and manufacturing processes to benefit both the supplier and buyer. This is the case for Ikeda Hoover Ltd (IHL). IHL makes and supplies the seating requirements for Nissan's daily production of 300 cars. To accommodate these expectations, IHL had to locate close to the Nissan plant and establish a manufacturing operation capable of dealing with up to 200 seating variations within a time window of approximately 2.5 hours.

\section{JIT And The Electronics Industry}

The JIT inventory management has flourished in the electronics industry. Samsung Electronics has been utilizing this philosophy since the late 1970s and serves as the industry benchmark. JIT, as Samsung is beginning to recognize, extends well beyond the arrival of goods from one firm to another. Through the interaction with few suppliers, close proximity of suppliers, tight relationships, and spreading the philosophy through the entire chain, great efficiencies can result. These efficiencies dramatically increase productivity by organizing and utilizing people, process and technologies in new ways. 
Consistent with JIT characteristics, Samsung keeps a limited number of suppliers. This allows for synergies to exist and prosper while eliminating variations and ensuring that perfect parts are delivered on time. Their approach to achieving this goal is to apply rigorous standards in evaluating the quality of the suppliers' products, ceasing to do business with those appraised to be in the lowest ten\% ("Respect subcontractor ...," 2003). This not only includes third party suppliers but their own subsidiary companies. By keeping the number of suppliers limited, Samsung realizes consistency and reliability. Further, by relying upon suppliers, especially those who understand Samsung as a result of long-term relationships, Samsung can gain competitive advantages in the form of intellectual capital. "Samsung Electronics set guidelines for depending on outsourcing for about $30 \%$ of their entire purchasing needs in an effort to gain access to various information, including trends in technology" ("Respect subcontractor ...," 2003). Advantages of working with a few suppliers can be realized that would otherwise be lost if working with larger numbers or no suppliers at all.

Another characteristic of operating under a JIT inventory system is having nearby suppliers. This can be especially critical when transportation of inputs can be costly or difficult to manage. Samsung utilizes Praxair as a supplier bulk and process gases necessary for production of liquid crystal displays. Praxair acquired an 18,000 square meter site adjacent to the Samsung complex for the helium and hydrogen supply systems. Mark Gruninger, the vice-president of Praxair Electronics realizes this and is quoted as saying:

As a key supplier of bulk gases to Samsung's new TFT-LCD manufacturing site, we are focused on bringing value to our customer through optimized gas usage and lowering the total cost of ownership; our 12-year relationship with Samsung has allowed us to prove our world-class supply capability of onsite, bulk and process gases. (Boden, 2005, p. 1)

Having nearby suppliers reduces costs and is especially critical when inputs are difficult to transport.

Samsung continues to value the repeat business that it receives from utilizing the same suppliers. They also look for ways of expanding these efforts. One such way was with the formation of the "collaboration portal" ("Samsung gains U.S. ..." (2003). The portal serves as a network to customers and suppliers releasing information on when, how, and how many units it will make of certain goods ("Respect subcontractor," 2003). To ensure its integrity, Samsung must have developed levels of trust that is only achieved through lasting relationships with their suppliers. The trust that is developed goes as far as allowing suppliers to enter the development room freely so they may better understand and be prepared to cooperate with Samsung's current work. Further, Samsung fosters these relationships by sharing information on product development and production plans with the suppliers and subcontractors on an accessible computer system.

Probably the most critical aspect of the JIT inventory system is getting as many levels of firms into the chain as possible. This ensures that the flow of processes is constant and accountable. Samsung encourages their suppliers to extend the JIT buying to their suppliers and pushes this technology forward to those it supplies. The collaboration portal previously mentioned serves to reduce inventory by providing information on purchasing, manufacturing, logistics and sales in real-time, subcontractors are made to cooperate with Samsung organically ("Respect subcontractors ..." 2003). This organic relationship can only be achieved if all of those involved cooperate with the entire group and have the ability to share information about one another's production and process. In addition, Samsung can pass this on to those it supplies allowing customers to identify exact production planning and supply schedules in real time, reducing management cost and maximizing business efficiency ("Respect subcontractors ..." 2003). Samsung serves as a conduit between its subsidiaries, partners, and customers so that everyone involved has a clear and real-time view of the status of purchase orders, sales, shipping, and inventory.

Vital to the chain of the JIT inventory system is effective communication lines that are at real-time and accessible to all. Samsung has been able to package this with its Global Samsung Business Network (GSBN). GSBN is a worldwide collaborative portal system enabling Samsung and its overseas subsidiaries, partners, and customers to have a clear and real-time view of the status of purchase orders, sales, shipping, and inventory (Boden, 2005). It has four process areas including the distribution of information, inventory planning, order fulfillment and 
payment, and service and support. In addition to these functions, it is automated through Excel that supports smaller business partners that do not have sophisticated systems to interact with GSBN. Consequently, the communication gives data at real-time for decision making that boosts revenues and profits while cutting costs. Further, inventory and sales data and projections are more accurate, enabling more accurate sales plans and better forecasts of product availability.

As Samsung's Senior Manager suggested, that through this system, out customers can identify exact productions planning and supply schedules in real time -- reducing management cost and maximizing business efficiency (Boden, 2005). The JIT philosophy as Samsung realizes should incorporate as many tiers along the supply chain as possible and should be passed along to its customers. The electronics industry is an ideal structure for such an environment due to each firm's dependence on others for critical parts that are ever evolving. Samsung continues to be a leader on this front always in search of conducting business better ensuring that they are leaders in an industry that is growing more competitive due to the advancements in technologies.

\section{JIT And The Healthcare Industry}

Another interesting application of the JIT philosophy is in the healthcare industry. Because of the uniqueness of a hospitals need to deliver services immediately and in unplanned quantities, makes inventories of medical supplies difficult to plan. Overall, it is much more difficult for a hospital to predict how many patients it will see in a given time frame and what their needs will be (Kowalski, 1991). Different medical services will require a different set of supplies, materials, equipment, and medications. Compared to the manufacturing industry, where production is predictable, and products are less variable for a given company, the healthcare industry is unpredictable and has many variations in its required service. While it is true that hospitals can track the number of patients each day, types of services required, and scheduled surgeries and treatments to help them plan the inventory requirements; they must have equipment and supplies available for the extraordinary busy day and the odd emergency procedure.

Further complicating the application of the JIT philosophy in healthcare is the amount of unique medications and equipment that is only available through specific suppliers. Because of this it looks as though the ability of hospital to reduce the number of suppliers, as required by JIT, would be virtually impossible. Also, because hospitals employee a large number of doctors, and each doctor has their own preference in equipment manufacturers and medications, reducing the number of suppliers may actually encourage certain doctors to leave the hospital and take their patients (customers) with them if they cannot get their preference in equipment, thus costing the hospital revenue.

Given the uniqueness, unpredictability, and user preference of the healthcare industry, how have hospital applied the JIT philosophy to their inventories? More specifically, how do hospitals implement JIT with their suppliers?

In order to take advantage of the JIT philosophy, hospitals must reduce their number of suppliers to a minimal level, and develop long-term relationships with them in order to assure quality and timeliness of deliveries. Many hospitals have taken this philosophy to the extreme by entering long-term contracts with a single supplier. This extreme form of JIT is known as stockless inventory.

The industry trend with hospital seems to be to sign large, long-term supply contracts with a single source. This single supplier will then provide all medical supplies required, often with daily deliveries. Some of the larger hospitals have supplier trucks parked at the receiving docks with certain disposable supplies available at any time. The hospital does not take receipt of the item until it is taken off the truck. This item is then consumed immediately. Hence the term stockless inventory.

This single source of supplies basically acts as a broker or warehouse. These suppliers often have access to multiple manufacturers of the same type of product, and often carry competing products. This helps solve the issue many hospitals face about different doctors preferring different equipment made by different manufacturers. Also, 
this allows the hospital to carry products by large variety of manufacturers while maintaining a single or only a few actual suppliers.

One such supplier is Baxter Healthcare Corp. Baxter agrees to long-term contracts, often five years or more, and in return they supply the hospital with daily deliveries of medical supplies. These supplies range from latex gloves, to syringes, to lab equipment, to operating room equipment and supplies. The contracts tend to be worth over $\$ 100$ million, and often allow Baxter to enter markets where they had little or no exposure. Baxter then takes advantage of it synergies by signing such agreements with multiply hospitals around the country. This allows Baxter to negotiate volume discounts with the manufacturers and pass those savings along to the hospitals. Hospitals in turn should have economic gains in with reduction or elimination of inventory, the reclamation of floor space previously dedicated to inventory, and supply cost reduction.

However, as Burnette (2004) notes, supply chain techniques going JIT inventory management, vendors have promoted initiative that have exploited hospitals and cost them very large sums in so-called supply chain management (SCM) efficiency. Ultimately, the basic concept is to reduce inventory costs. Total inventory cost should be the goal, not such minimizing the unit costs of selected items. It is not the bits of costs that matter to the customer, but rather the total costs that must be competitive (Smith and Offodile, 2007). It is the net effect or sensitivity of these items to the total supply costs that msut be studied in detail.

This suggests that there are some pitfalls with the application of the JIT philosophy. Hospitals must be able to evaluate the actual cost benefit of a stockless program, as well as understand the basic concepts of inventory management. Simply outsourcing the problem does not cure it, and in fact may make it worse.

Another problem with JIT in a hospital setting is backup plans in cases of emergencies or glitches in the system. In a perfect world, demand is predictable and the system works to perfection. However, real world issues do occur from simple traffic jams to total disruption of the distribution system, as occurred during the September 11, 2001 attacks. Hospitals cannot simply shut down or turn away patients while waiting for the supply truck to arrive. To counteract these scenarios, most hospitals still maintain an emergency supply of "critical items" in case such events occur (Rosenbaum and Borzo, 1991). Therefore, hospitals cannot reap the complete benefit that these JIT systems theoretically provide.

As we've seen, hospitals can and do have JIT partnerships with their suppliers. In fact, some hospitals take these relationships to the extreme by relying on a single vendor and entering long-term contracts often of five years or more. Moreover, often these contracts are renewed once they are expired. However, hospitals tend to have a "hands off" approach once the supplier is chosen. This means that there are no competitive bids for supplies. The vendor simply provides the supplies at some agreed upon price. This does insure the supplier of constant business, without the fear that hospitals will try to vertically integrate their supply chain. The extent that the suppliers practice JIT philosophies is unclear. These companies are large and need to be able to provide all supplies within a moments notice. This would become difficult to do if they did not carry an inventory of the oddest supply. These suppliers basically replace the storage rooms of the hospitals.

\section{JIT And Vertical Integration And The Steel Industry}

U.S. Steel Corporation (U.S.S.) is the largest integrated steel producer in North America, and one of the largest integrated flat-roll producers in Central Europe, with 19.4 million tons of annual domestic steel making capability. U.S.S. produces steel slabs, which are rolled into steel coils and shipped to various manufacturers for processing. U.S.S. sells a variety of steel sheet, tubular and tin products, as well as coke and taconite pellets ("A new day for U.S. steel." 2003). In December, the steel industry was faced with higher costs for raw materials, including scrap, coke, iron ore, and raw material surcharges. The 'China Effect' servicing to drive up raw material costs, freight rates, and steel prices around the world impacted the North American Steel industry ("United States Steel Corporation reports record ..." 2004). It is expected that China's demand for steel and raw materials should keep prices up and import levels down. U.S.S. domestic operations recently benefited from increased prices for 
tubular products and lower purchased coke costs, while costs increased for natural gas, scrap and coal (Bennett, 2005a; 2005b).

U.S.S. has maintained a cost advantage by taking advantage of few suppliers by way of being fully integrated and taking part in all points of the value chain in converting raw materials into finished goods. They employ economies of scale and vertical integration in their supply chain. U.S.S. has access to natural resources needed in the manufacturing process, including the primary raw materials used in production, iron ore, and coke. Its Minnesota Ore Operations include iron mine and processing facilities in Minnesota (Minntac) and Keewatin Taconite. It also owns four coke processing facilities, Gary Works, Great Lakes Works, and Granite City Works, where pulverized coal is baked to produce coke for the steel making process. U.S.S. ships its raw materials such as iron ore, coal, coke and limestone to its processing plants by using its wholly owned transportation company (Transtar), which includes rail, ship and barge. U.S.S. keeps seven to 30 days raw materials on hand in case shipments are delayed; however, raw materials are delivered in time for production (Usher, 2003).

U.S.S. also takes advantage of its own Logistics services, U.S.S. Logistics Services, which provides transportation management, logistic planning and administration, operations management, contract management, and handles both domestic and international transportation. U.S.S. Logistics Services has been recognized and benchmarked by other steel production companies.

Scrap is another resource used in steel production. U.S.S. also recycles scrap, which accounts for $25 \%$ of U.S.S. scrap-related needs. More than 70 million tons of scrap was recycled in 2002 that accounted for an overall recycling rate of $71 \%$ ("Steel and sustainability." (2003). U.S.S. sold its coal mines on June 30, 2003. Prior to the sale, USS owned coal mines produced $25 \%$ of the coal U.S.S used. Currently, U.S.S. relies on a handful of suppliers domestically. The following statement was attributed to G. Haggerty, Executive V.P., Treasurer, and CFO of U.S.S.:

Haggerty said U.S. Steel's major suppliers of coal, nearly all of which had declared force majeure, are operating and some are increasing capacity. "We continue to work through a number of force majeure situations that have plagued the coal industry in recent months. We are still having difficulty getting the right quality coal in sufficient quantities to the right locations. Therefore, we continue to operate our coke batteries at less than capacity." (Petry, 2004, p. 443)

U.S.S. recently acquired plant in Serbia relies on $100 \%$ purchased iron ore and coal. According to Petry (2004), raw material costs have been a concern in Serbia, since that operation relies on 100\% purchased coke and iron ore. They must improve their European raw material position is and take steps to reduce the financial impact through alternative sourcing of incoming materials, such as shipping iron ore from their U.S. operations to Serbia and taking advantage of their operations just to the north in Slovakia.

Further integration along the supply chain is accomplished by providing finishing services for finished production (steel coils) handled by domestic plants, and both international and domestic joint ventures with companies which provide coating services. U.S.S. also provides shipping and logistics services for its finished goods, and is strategically located along waterways, railways, and facilities. U.S.S. takes advantage of the synergies of the newly acquired facilities of National Steel. Outbound shipping methods include rail, barge, and truck.

Vertical integration provides benefits of cost advantage, control over suppliers, and guaranteed delivery of raw materials in times of shortage and sharp price increases. U.S.S. leverages forecasting to estimate demand, availability, and prices of raw materials both domestically and abroad, and also supplies other steel companies with raw materials. U.S.S. remains America's largest steel producer, and one of the lowest cost producers of steel in the world (Apelt, 2004). U.S.S. continues to forge a presence globally, and takes advantage of newly developed synergies both here and abroad 


\section{GENERAL CONCLUSIONS AND IMPLICATIONS OF JIT AND SUPPLY CHAIN MANAGEMENT}

As evident from an inspection on the operational efficiencies associated with a select number of industries in the U.S. and it global strategic initiatives, the automotive and electronic industries rely heavily on information sharing (Denzel, 2004; Smith, 2004; Smith and Manna, 2004). The healthcare industry appears to seeking out long-term contracts with suppliers in order to assure quality and timeliness of deliveries as its critical success factor. The U.S. steel industry has elements of the JIT philosophy, but has been forced to vertically integrate many of its productions globally, due to the rising costs of raw materials. However, in JIT systems, the goal is to derive an integrated set of activities designed to achieve high-volume production using minimal inventories of raw materials, work in process, and finished goods. Thus, parts arrive to the next workstation, just in time and are completed and move through the operation quickly. Therefore, the logic of JIT is that nothing will be produced until it is needed. Need is created by the actual demand of the product when item is sold, the market hence pulls a replacement from the last position in the system. "JIT demands high levels of quality at each stage of the process, strong vendor relations, and a fairly predictable demand for the end product" (Chase, Aquilano, and Jacobs, 1998, p. 324). The concept, combined with flexible manufacturing systems, with extremely small and standardized setup times, may significantly reduce the needs for long production runs and the need for long term forecasting requirements.

\section{REFERENCES}

1. $\quad$ A new day for U.S. steel. (2003). U.S. Steel News, Issue 2, p. 2-9.

2. Apelt, B. (2000). The Corporation, a Centennial Biography of United States Steel Corporation, 1901-2001. Pittsburgh, Pennsylvania, Cathedral Publishing.

3. Bennett, A. (2005a).Steel market highlights. AMM (American Metal Market Research). 112(69): 1.

4. Bennett, A. (2005b). The road ahead for USS, The next chapter will revolve around raw materials and auto steel. AMM (American Metal Market Research. The Monday Edition, 112(49): 10.

5. Boden, J. (2005). Praxair expands its relationship with Samsung to supply bulk gases in newest Korean flat panel display factory. Praxair Technology Newsroom.

6. Burnette, J.H. (2004). The missing link in the supply chain. Hospitals Strategies, Inc.

7. Camuffo, A. and Volpato, G. (2000). Making manufacturing lean in the Italian automobile industry: the trajectory of Fiat. Department of Business Economics and Management-University Ca' Foscari, Venice, Italy. Online. Available at: http://www.univ-evry.fr/labos/gerpisa/actes/10/10-2.pdf.

8. Chase, R. B., Aquilano, N.J., and Jacobs, F.R. (1998). Production and Operations Management: Manufacturing and Services, 8 th Ed. Irwin and McGraw-Hill Pub. Co.: Boston, MA.

9. Denzel, N. (2004). Do more with less in an environment of change. Today's IT-Information Technology Newsletter.

10. Domingo, R.T. (1995). Just-in-time: an Asian view. RTD Online.com. Online. Available at: http://www.rtdonline.com/art63b.htm.

11. Doran, D. (2001). Synchronous supply: an automotive case study. European Business Review, 114-124.

12. Evidence from the business. (2002). Management Literature, 41-71. Online. Available at: http://www.rand.org/publications/MR/MR865/MR865.chap5.pdf.

13. Foudy, J.F. (2007). Shareholder value and the German and Japanese models: a case study of the automobile sector. Yale University, 1-57. Online. Available at: http://www.yale.edu/leitner/pdf/CPEDLDC-Foudy.pdf

14. Heizer, J., and Render, B. (2004). Operations Management (7th Ed.). New Jersey: Prentice Hall.

15. Kowalski, J.C. (1991). Inventory to go: can stockless deliver efficiency? Healthcare Financial Management.

16. Petry, C. (2004, September). Big 3 steelmakers expect banner Year, Metal Center News Radnor, 44(10): 44-49.

17. Respect subcontractor, Samsung CEOs equally; Lee: Good business. (2003, July 15). Korea Herald, p. 1

18. Rosenbaum, S. and Borzo, G. (1991). Stockless distribution hits lull after boom. Health Industry Today.

19. Samsung gains U.S. \$2.9 million annually with portal solution. (2003). Microsoft Corporation. Microsoft Windows Server System Customer Solution Case Study. 
20. Smith, A.D. (2004). Empirical exploration for a Product Data Management (PDA) System at a major telecommunications firm. Industrial Management and Data Systems, 104(5/6): 513-525.

21. Smith, A.D. and Flanegin, F.R. (2004). E-procurement in the health care industry: Enhancing supply chain management. International Journal of Electronic Healthcare, 1(2): 176-198.

22. Smith, A.D. and Manna, D.R. (2004). Strategic disintermediation within the context of e-commerce: The effect on distributors and re-sellers. The Journal of the American Academy of Business, Cambridge, 5(1/2): 374-380.

23. Smith, A.D. and Offodile, O.F. (2007). Exploring forecasting and project management characteristics of supply chain management. International Journal of Logistics and Supply Management, 3(2): 174-214.

24. Steel and sustainability. (2003). U.S. Steel News, Issue 3, p. 6.

25. United States Steel Corporation reports record 2004 fourth quarter and full-year results. (2004, January). United States Steel Corporation-Press Release, PRNewswire-FirstCall, p.1.

26. Usher, T. (2003). United States Steel Corporation, 2003 Annual Report, Chairman’s Message, p. 1.

\section{NOTES}


NOTES 